\title{
PERFIL SOCIOECONÔMICO DOS MARISQUEIROS E CONDIÇÕES HIGIÊNICAS ADOTADAS NA CADEIA PRODUTIVA DE OSTRA (MOLLUSCA, BIVALVIA)
}

\author{
Eliane Braga Ribeiro \\ Luciana da Silva Bastos ${ }^{2}$ \\ Zafira da Silva de Almeida ${ }^{3}$ \\ Raimunda Nonata Fortes Carvalho Neta ${ }^{4}$ \\ Francisca Neide Costa $^{5}$
}

RIBEIRO, E. B.; BASTOS, L. da S.; ALMEIDA, Z. da S. de.; CARVALHO NETA, R. N. F.; COSTA, F. N. Perfil socioeconômico dos marisqueiros e condições higiênicas adotadas na cadeia produtiva de ostra (Mollusca, Bivalvia). Arq. Ciênc. Vet. Zool. UNIPAR, Umuarama, v. 19, n. 4, p. 209-214, out./dez. 2016.

RESUMO: O consumo de ostras na forma in natura exige muito cuidado e práticas higiênicas e sanitárias corretas pelos marisqueiros e demais manipuladores desse alimento durante o processo de beneficiamento à comercialização, para que não haja contaminação por microrganismos patogênicos e deteriorantes. O presente estudo teve como objetivo avaliar o perfil socioeconômico de marisqueiros e as condições higiênicas e sanitárias praticadas na cadeia produtiva de ostras do gênero Crassostrea desde a extração até a comercialização. No período de janeiro a abril de 2014, por meio da técnica de amostragem "Bola de Neve" foram selecionados 40 marisqueiros na Ilha de São Luís - MA, os quais foram entrevistados utilizando-se questionário semiestruturado. De acordo com os resultados, a maioria dos marisqueiros, possui ensino fundamental incompleto, faixa etária entre 21 e 30 anos e encontram-se em união estável ou casados. Parte das ostras são extraídas em bancos naturais na área de estudo, enquanto outra parte é proveniente de atravessadores oriundos de outros municípios maranhenses. Após a aquisição, pode demorar até três dias para serem comercializadas. Concluiu-se que as condições higiênicos sanitárias adotadas na atividade de extração de ostras até a comercialização são insatisfatórias, indicando falta de boas práticas em todas as etapas ao longo do processo de produção, o que pode representar riscos à saúde da população apreciadora do consumo in natura desse bivalve. Além disso, indica a necessidade de fiscalização dessa atividade, já que os organismos são transportados de forma inadequada e passam muito tempo até chegar ao consumidor final.

PALAVRAS-CHAVE: Atividade extrativista. Boas práticas. Moluscos bivalves. Segurança alimentar.

\section{SOCIO-ECONOMIC PROFILE OF SHELLFISH COLLECTOR AND HYGIENIC CONDITIONS IN THE PRODUCTION CHAIN OF OYSTERS (MOLLUSCA, BIVALVIA)}

\begin{abstract}
Consumption of fresh oysters requires very careful and correct hygienic and sanitary practices by shellfish collectors and other food handlers during the handling process to marketing, in order to avoid contamination by pathogenic microorganisms or deterioration. This study aimed to evaluate the socio-economic profile of shellfish collectors and the hygienic conditions applied in the production chain of Crassostrea oysters from extraction to marketing. In the period from January to April 2014, through a snowball sampling technique, a total of 40 shellfish collector were selected in Ilha de São Luís - MA. These collectors were interviewed using a semi-structured questionnaire. According to the results, most shellfish collector had not completed elementary school, aged between 21 and 30 years and married or co-habiting. Part of the oysters is extracted from natural stocks in the study area, while other oysters come from middlemen who bring them from other cities in Maranhão. After acquisition, they can take up to three days to be marketed. Therefore, it was concluded that although it is an important source of income, hygienic and sanitary conditions adopted in the oyster extraction activity are unsatisfactory, indicating a lack of good practices throughout the production process, which can pose risks to the population who consume this bivalve fresh. It also shows the need for supervision of the activity, since the organisms are improperly transported, spending much time until reaching the end consumer.
\end{abstract}

KEYWORDS: Bivalve mollusk. Extraction activity. Food safety. Good practice.

\section{PERFIL SOCIOECONÓMICO DE MARISQUEROS Y CONDICIONES HIGIÉNICAS ADOPTADAS EN LA CADENA PRODUCTIVA DE OSTRA (MOLLUSCA, BIVALVIA)}

RESUMEN: El consumo de ostras en la forma fresca, in natura, requiere gran cuidado y prácticas higiénicas sanitarias cor-

DOI: https://doi.org/10.25110/arqvet.v19i4.2016.6098

${ }^{1}$ Mestre em Ciência Animal, Universidade Estadual do Maranhão - UEMA. Cidade Universitária Paulo VI - Caixa Postal 09 - São Luís - MA. elianeribeiro biologa@gmail.com

${ }^{2}$ Mestranda em Saúde e Ambiente, Universidade Federal do Maranhão - UFMA. Av. dos Portugueses, 1966 - Bacanga, São Luís - MA, 65080-805. lucianabastos79@gmail.com

${ }_{3}^{3}$ Professora Dra. da Universidade Estadual do Maranhão - UEMA. zafiraalmeida@hotmail.com

${ }^{4}$ Professora Dra. da Universidade Estadual do Maranhão - UEMA. raimundafortes@yahoo.com.br

${ }^{5}$ Professora Dra. da Universidade Estadual do Maranhão - UEMA. franeidec@yahoo.com.br 
rectas por los marisqueros y otros manipuladores de ese alimento durante el proceso de beneficiación a la comercialización, para que no haya contaminación por microorganismos patógenos y de deterioración. Este estudio tuvo como objetivo evaluar el perfil socioeconómico de marisqueros y las condiciones higiénicas sanitarias practicadas en la cadena productiva de ostras del género Crassostrea, desde la extracción hasta la comercialización. En el período de enero a abril de 2014, a través de la técnica de muestreo "Bola de Nieve" se seleccionaron 40 marisqueros en la Isla de São Luís - MA, que fueron entrevistados mediante cuestionario semiestructurado. De acuerdo con los resultados, la mayoría de los marisqueros tiene enseñanza primaria incompleta, con edades comprendidas entre 21 y 30 años y se encuentran en unión estable o casados. Parte de las ostras son extraídas en bancos naturales en el área del estudio, mientras otra parte proviene de los intermediarios de otros municipios de Maranhão. Después de la adquisición, puede tardar hasta tres días para que sean comercializadas. Se concluye que las condiciones higiénicas sanitarias adoptadas en la actividad de extracción de ostras hasta la comercialización son insatisfactorias, indicando falta de buenas prácticas en todo el proceso de producción, lo que puede plantear riesgos a la salud de la población aficionada al consumo in natura de ese bivalvo. Además, indica la necesidad de supervisar esta actividad, ya que los organismos son transportados inadecuadamente y pasan mucho tiempo para llegar al consumidor final.

PALABRAS CLAVE: Actividad extractiva. Buenas prácticas. Moluscos bivalvos. Seguridad alimentaria.

\section{Introdução}

$\mathrm{Na}$ atividade pesqueira, os recursos aquáticos devem ser processados de modo a garantir a segurança alimentar e a sanidade dos alimentos produzidos (BRASIL, 2009). Sobretudo, em se tratando de moluscos bivalves, cujo consumo de algumas espécies é feito de forma in natura. Em vários Estados do Brasil, a extração desses moluscos garante a subsistência de parte da comunidade pesqueira, tanto em termos de consumo, como de comercialização (RAMOS et al., 2010).

Dentre os moluscos bivalves extraídos, destacam-se as ostras do gênero Crassostrea, por se tratarem de um alimento muito apreciado pelas populações litorâneas, todavia podem representar um risco de ocasionar doenças aos consumidores, visto que são animais de hábito alimentar filtrador e são consumidos crus (PEREIRA et al., 2006). Essa forma de consumo exige maior cuidado e práticas higiênicas e sanitárias corretas pelos marisqueiros de ostras e demais manipuladores desse alimento no processo de beneficiamento e comercialização, para que não haja contaminação por microrganismos patogênicos e deteriorantes.

A cadeia produtiva de alimentos é composta pela sequência de etapas e operações envolvidas na produção, processamento, distribuição, estocagem e manuseio do alimento e seus ingredientes, desde a aquisição da matéria-prima até o consumidor final (ABNT, 2006). A adoção de boas práticas ao longo das etapas de produção de um alimento se constitui em um conjunto de medidas que quando aplicadas, tendem a reduzir os riscos e os perigos para a sua contaminação (CASTILHO-WESRPHAL et al., 2008) minimizando a ocorrência de doenças transmitidas por alimentos (DTA's).

Dentre os principais fatores associados às enfermidades de origem alimentar existem as más condições de higiene na manipulação dos alimentos, o uso equivocado da relação tempo-temperatura, más condições de armazenamento e conservação dos alimentos e inadequações na estrutura física dos locais de venda (CAVALCANTI et al., 2014).

Em estudo realizado no Município de Valença (Bahia) em três estabelecimentos comerciais de ostras e demais frutos do mar, foram verificadas falhas no controle das etapas de aquisição e fluxo de produção, preparação dos alimentos e treinamento dos manipuladores, incorrendo na comercialização de ostras com elevadas contagens de Staphylococcus coagulase positiva (SANTOS; EVANGELISTA-BARRETO; SILVA, 2014).
Considerando-se a importância para a saúde pública e o fornecimento de um alimento sanitariamente seguro, somada a ausência de estudos qualitativos sobre as condições e práticas adotadas pelos marisqueiros ao longo da cadeia produtiva de ostras em municípios maranhenses, objetivou-se avaliar o perfil socioeconômico desse grupo de pescadores e as condições higiênicas e sanitárias praticadas desde a extração até a comercialização na cadeia produtiva de ostras do gênero Crassostrea na Ilha de São Luís - MA.

\section{Material e Métodos}

A pesquisa foi realizada no período de janeiro a abril de 2014 com integrantes da comunidade marisqueira, na Ilha de São Luís, que localiza-se ao Norte do Estado do Maranhão, região Nordeste do Brasil (IBGE, 2014). É constituída pelos municípios de São Luís, São José de Ribamar, Paço do Lumiar e Raposa (Figura 1).

\section{Figura 1: Localização da Ilha de São Luís - MA, Brasil.}

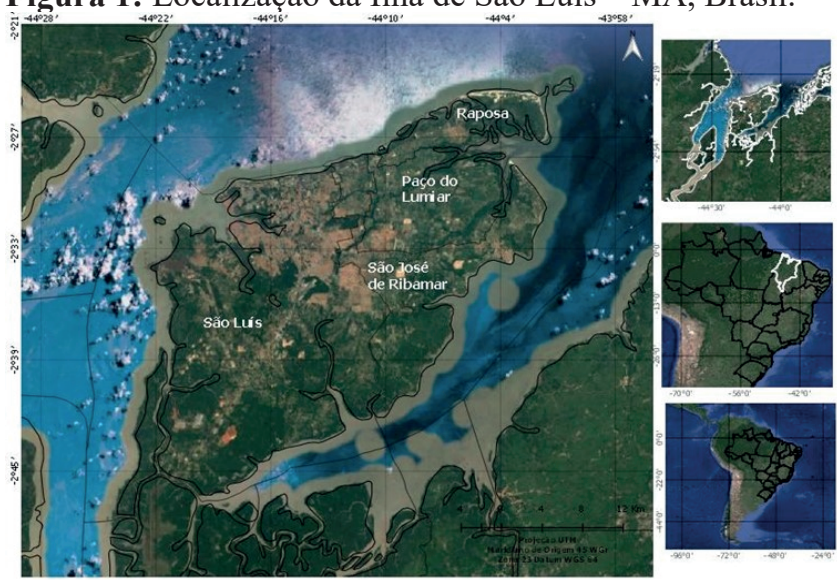

Para a realização da pesquisa nestes municípios, foi obtida a autorização de pesquisa científica $n^{\circ}$ 003/2014 (processo 21504/2014) por meio da Secretaria de Meio Ambiente do Estado do Maranhão-SEMA, devido integrarem a unidade de conservação estadual denominada de Área de Proteção Ambiental -APA de Upaon-Açu/ Miritiba/Alto Preguiça.

$\mathrm{Na}$ área de estudo foram entrevistados 40 marisqueiros, utilizando-se questionário semiestruturado de cunho qualitativo e quantitativo, abordando questões sobre: a origem das ostras, os procedimentos realizados ao longo das etapas do processo de mariscagem de ostras até a sua pri- 
meira comercialização, percepção higiênicas e sanitárias e questões socioeconômicas (nível de renda, local e condições de moradia, idade e escolaridade).

A técnica de amostragem utilizada foi do tipo "Bola de Neve" ou Snowball Sampling. Este método utiliza cadeia de referências, onde os entrevistados iniciais da população alvo da pesquisa informam novos membros, os quais por sua vez, farão novas indicações e assim por diante, até que as informações obtidas comecem a se repetir (BALDIN, MUNHOZ, 2011).

A abordagem aos marisqueiros foi realizada nas residências, nos pontos de trabalho e/ou locais de comercialização de ostras. Para a aplicação dos questionários foi solicitada a autorização dos entrevistados por meio da leitura do termo de consentimento prévio e assinatura do mesmo.

As informações obtidas foram calculadas em software Microsoft Office Excel, versão 2007. Para análise e interpretação dos dados empregou-se estatística descritiva onde os dados foram expressos em gráficos e em porcentagem.

\section{Resultados e Discussão}

\section{Perfil sócio econômico dos marisqueiros}

Os marisqueiros entrevistados tinham em média 33 anos, com variação entre 17 e 64 anos, sendo a faixa etária com maior representatividade entre 21 e 30 anos, seguida de 31 a 40 anos (Figura 2). A maioria tem como estado civil, casado ou união estável e possui 2 (dois) a 3 (três) filhos. Observou-se que há predominância de adultos do sexo masculino no exercício de uma atividade do setor primário que contribui para o desenvolvimento da economia local. Contrariamente, Monteles et al. (2009) caracterizou a predominância $(96 \%)$ de mulheres atuando na mariscagem de sarnambi (Anomalocardia brasiliana) e tarioba (Iphigenia brasiliensis) no Município de Raposa - MA.

Figura 2: Frequência das faixas etárias dos marisqueiros de ostras, Ilha de São Luís - MA, 2014.

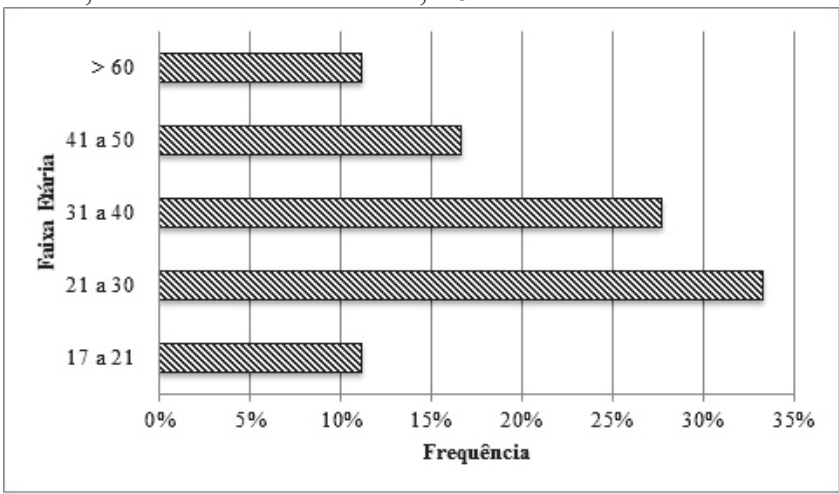

Em relação ao grau de escolaridade, a maior parte dos marisqueiros tem ensino fundamental incompleto (Figura 3), justificado pela necessidade de trabalhar para sustentar a família, baixo rendimento escolar, além da falta de escolas onde moravam. Diversos trabalhos apontam que frequentemente os pescadores têm baixa escolaridade. Santos et al. (2011) observaram-se que 19\% dos pescadores entrevistados no município de Raposa - MA são analfabetos e $49 \%$ têm ensino fundamental incompleto. Cavalcante et al. (2013) registraram que $80 \%$ dos pescadores na Reserva Extrativista RESEX de Canavieiras no Estado da Bahia possuíam apenas o nível fundamental.

Figura 3: Frequência do grau de escolaridade dos marisqueiros de ostras, Ilha de São Luís - MA, 2014.

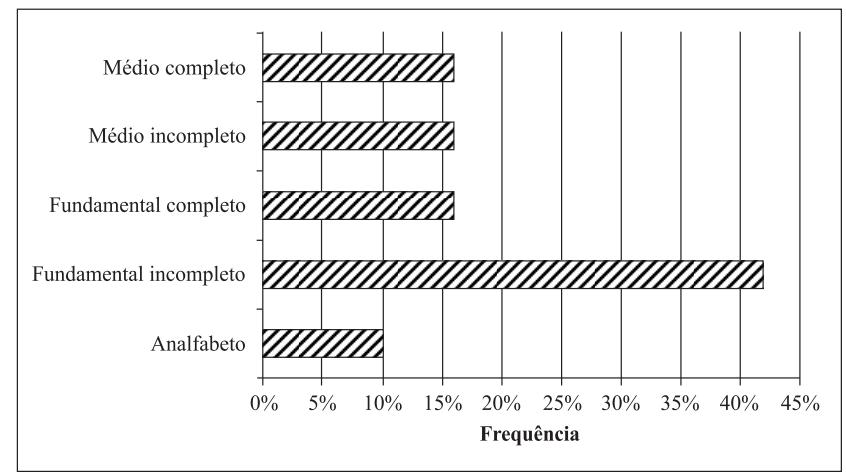

Quanto à naturalidade, a maioria é proveniente dos municípios maranhenses de Urbano Santos, Cândido Mendes, Barreirinhas, Cururupu, Pinheiro e Primeira Cruz, enquanto o segundo percentual é oriundo principalmente dos municípios de Raposa e Paço do Lumiar (Ilha de São Luís - MA), o restante é originário de outros Estados brasileiros (Alagoas, Ceará e Pará) (Figura 4). A maioria (84\%) reside em casa própria de alvenaria, com luz elétrica e água encanada, (53\%) possui banheiro dentro de casa, (84\%) não possui instalação de esgoto, mas é provida de fossa seca ou séptica $(68 \%)$.

Figura 4: Locais de origem dos marisqueiros de ostras, Ilha de São Luís - MA, 2014.

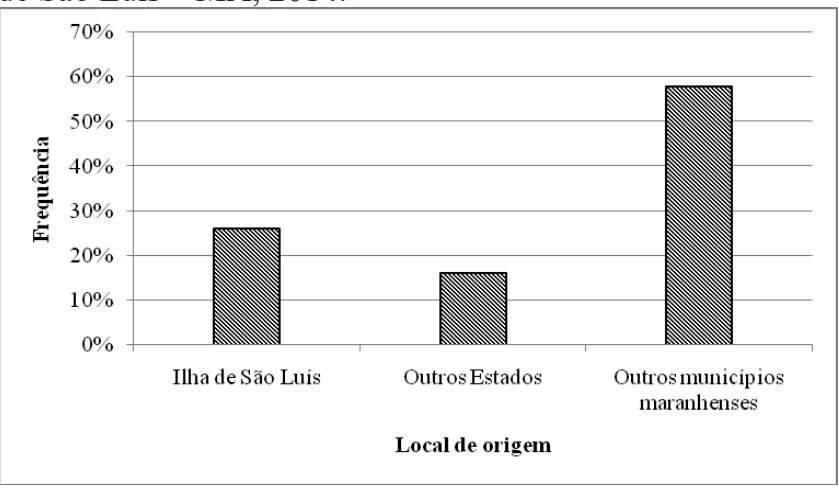

Em relação à organização da atividade da mariscagem, a maior parte (84\%) afirmou não ser cadastrado em nenhum tipo de associação, cooperativa ou colônia de pescador. Embora, já estivessem exercendo a atividade (ostreiro ou catador de ostra), em média há 9 anos, considerando-se que houve uma variação entre um e quarenta anos entre o mais recente na atividade e o mais antigo. A minoria é cadastrada de forma generalizada como pescador, independente do produto que pesca, pois não existe um cadastro específico para a categoria de marisqueiro ou ostreiro. $\mathrm{O}$ termo mariscagem é aplicado de forma abrangente e designando a atividade de extração ou catação de moluscos e crustáceos.

Maneschy (1993) explica que a razão para a falta de mobilização da categoria traduz certamente no fato de que os 
trabalhadores em questão incorporam a imagem desvalorizada e estereotipada de seu trabalho que predomina na sociedade, o que inibe a tomada de consciência de sua importância enquanto categoria profissional.

Observou-se que 63\% dos indivíduos amostrados têm como principal atividade a extração e venda de ostras, obtendo, no final do mês o valor correspondente a um salário mínimo. Porém, trabalham com outros recursos pesqueiros (peixe, sarnambi, camarão, sururu, siri, caranguejo e turu), conforme a disponibilidade no ambiente, valor de mercado e necessidade de incrementar a renda. Além de, secundariamente prestarem serviços como pedreiros.

Para Lima, Dória e Freitas (2012) o baixo nível de instrução vincula ainda mais os pescadores à atividade da pesca. Isto porque, têm menos acesso a novos conhecimentos, prejudicando o aperfeiçoamento para o desempenho das atividades que requerem maior qualificação e melhor remuneração.

Nishida, Nordi e Alves (2008) observaram que os catadores de moluscos de comunidades situadas às margens dos estuários do Rio Paraíba do Norte, no Estado da Paraíba, apresentaram renda inferior a um salário mínimo. Monteles et al. (2009) verificaram que a mariscagem é a principal atividade e fonte de renda para $58 \%$ dos entrevistados, no $\mathrm{Mu}-$ nicípio de Raposa, na Ilha de São Luís, enquanto que para os demais consiste apenas em um ganho adicional à renda de suas famílias, com isso buscavam outras alternativas financeiras (produção de artesanato com as conchas dos organismos capturados e fabricação de rendas e roupas).

Parte das ostras comercializadas era coletada pelos próprios marisqueiros, enquanto a outra parte é comprada de atravessadores oriundos dos municípios de Tutóia e Humberto de Campos - MA. As ostras desses municípios, são maiores, são transportadas em carro baú acondicionadas em sacos de ráfia e distribuídas diretamente nas casas dos marisqueiros nas comunidades tradicionais chamadas de Cumbique, Alto Farol do Araçagi e Pirâmide. Essas ostras são mescladas, e conforme o tamanho, são vendidas no valor entre $\mathrm{R} \$ 10,00$ a $\mathrm{R} \$ 15,00$ a dúzia.

\section{Procedimentos para extração das ostras}

A maioria dos marisqueiros relatou que o processo de extração das ostras é feito em bancos naturais localizados principalmente nos municípios de Raposa, Paço do Lumiar e São José de Ribamar. Conforme a distância, o acesso às áreas estuarinas é feito a pé ou utilizando canoas. As ostras são coletadas no período de maré vazante, os marisqueiros têm como critério de seleção, verificar se as ostras estão fechadas, o tamanho e a coloração da concha. Utilizam ferramentas de corte (como facão e faca) para extração dos moluscos; balde e sacos de ráfia para acondicioná-los; e para proteção pessoal usam sapatos, camisa de manga comprida, luva e óleo de motor, como repelente.

A frequência de coleta ocorre em 55\% dos casos, uma vez por semana e em $38 \%$ duas vezes, sendo considerada a melhor época do ano para a extração os meses de julho a dezembro, correspondente ao período de estiagem ("verão"). Já no período chuvoso, conforme relato, as ostras apresentam-se menores e têm maior tendência de morrer, devido ao maior volume de água doce.
Montanhini Neto et al. (2013) verificaram que a redução da salinidade no sistema estuarino, por conta do maior aporte de água da chuva pelos rios, foi uma das variáveis ambientais que contribuiu para o comprometimento da taxa de crescimento e sobrevivência de ostras Crassostrea na Baía de Guaratuba-Paraná. Conforme a variação da salinidade, os limites mínimos e máximos atingidos podem ser incompatíveis para a tolerância das ostras (GUIMARÃES et al., 2008).

Em relação ao processo de extração, este consiste na raspagem da raiz do mangue para retirar as ostras incrustadas ou são retiradas uma de cada vez. Alguns afirmaram que cortam ou batem a raiz para fazer a sua retirada e em seguida as acondicionam.

\section{Tratamento dado ao produto coletado}

A quantidade de ostras extraídas variou entre 35 a 40 dúzias por coleta. Alguns marisqueiros relataram que retiram o excesso de lama das ostras com água do mar e transportam para casa, onde são feitos os procedimentos de limpeza e conservação do produto, que consiste entre um a três enxagues, utilizando água da rede de abastecimento local, em seguida é feito o acondicionamento em recipiente plástico, na parte inferior da geladeira, onde ficam até o momento da venda do molusco. Na maioria das vezes a comercialização ocorre em um dia, porém pode demorar até três dias.

Embora os marisqueiros considerem esses procedimentos suficientes para a conservação das ostras, ressalta-se que tais procedimentos são realizados de forma rudimentar e em condições precárias de higiene e de infraestrutura, expondo o alimento à contaminação ambiental, seja por agentes causadores de doenças ou de deterioração. As ostras, antes da comercialização, não passam por tratamento de depuração. Esse fato é preocupante para a saúde da população consumidora, visto que são alimentos consumidos crus, e as áreas de coleta estão sujeitas ou próximas de pontos de descarga de lixo e esgoto, provenientes do entorno urbanizado, além de óleo das embarcações pesqueiras.

Para Pereira et al. (2006) as ostras consumidas cruas e originadas a partir de áreas contaminadas ou manipuladas em condições higiênicas e sanitárias precárias contribuem para aumentar o risco de doenças veiculadas por alimentos. Enfermidades como infecções ou intoxicações alimentares podem ocorrer com a ingestão de alimentos crus ou minimamente cozidos, caso estejam contaminados (BRAGA; FERREIRA, 2013). Welker et al. (2010) afirmam que as doenças transmitidas por alimentos constituem um grande problema de saúde pública, tanto no Brasil como nos demais países, sendo responsáveis por elevados custos econômicos e sociais.

Os pescados de modo geral exigem diversos cuidados tanto em relação ao manuseio, como durante o processo de captura e estocagem em caixas térmicas (VIEIRA, 2004). Procedimentos de manipulação em contato direto com o alimento ou com auxílio de equipamento, se realizado de forma precária e mesmo em condições higiênicas e sanitárias deficientes, interagem de forma sinérgica influenciando negativamente a qualidade do produto.

Os tecidos moles das ostras, apesar de estarem protegidos pela concha, podem ser contaminados durante as etapas da sua cadeia produtiva. Basti et al. (2006) acrescen- 
tam que alguns microrganismos fazem parte da microbiota natural dos pescados, mas que se forem ingeridos pelo ser humano, podem causar doenças.

\section{Comercialização e procedimentos higiênicos}

Para realizar a comercialização, os marisqueiros armazenam as ostras em caixa de isopor contendo gelo. Quanto ao tempo para comercialização do produto, a maioria dos entrevistados, afirmaram que demoram em torno de 2 (dois) a 3(três) dias, após a sua obtenção. Moreira Junior (2010) menciona que após a retirada do pescado do seu ambiente natural, a ação microbiológica e enzimática do processo de deterioração inicia-se rapidamente e a prática mais comum para conservá-lo em boas condições para consumo é deixá-lo em baixas temperaturas.

O gelo utilizado por $37 \%$ dos marisqueiros é obtido no comércio e/ou produzido em casa, $32 \%$ utilizam somente o gelo comprado e 5,2\% usam somente o gelo caseiro. Vieira (2004) afirma que o gelo, apesar de não ser um meio de cultivo para bactérias, por falta de nutrientes necessários ao seu desenvolvimento, pode funcionar como um carreador desses microrganismos para o alimento em questão.

Sobre os procedimentos higiênicos necessários para a comercialização das ostras os dados obtidos mostraram que os marisqueiros consideram principalmente a lavagem das mãos (Figura 5). Apesar de mostrarem ter ciência de algumas práticas corretas de manipulação, muitos cuidados mencionados por esses trabalhadores não foram observados durante o exercício da sua atividade comercial.

Observou-se que existe a necessidade de orientação sobre as boas práticas de manipulação, quanto aos cuidados com a higiene pessoal e para a manutenção da qualidade do alimento por eles capturados e comercializados.

Para Mello et al. (2010) é imprescindível melhorar a qualidade dos produtos e serviços ofertados pelos manipuladores de alimentos, assim como realizar ações e atividades educativas para capacitá-los quanto aos hábitos higiênicos e sanitários adequados a serem praticados diariamente.

Figura 5: Procedimentos adotados pelos marisqueiros durante a comercialização das ostras, Ilha de São Luís - MA, 2014.

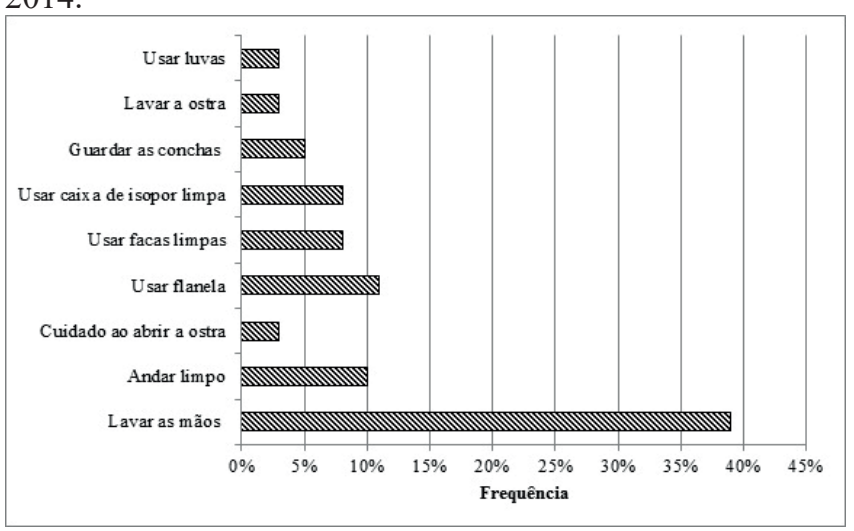

Os dados obtidos são importantes, pois podem nortear mais possibilidades de estudos no sentido de difundir a importância da adoção de práticas higiênicas e sanitárias no processo de extração, beneficiamento e comercialização de moluscos bivalves consumidos in natura. Consequentemente, propiciar qualidade e um alimento seguro para a população e maior rentabilidade para os marisqueiros da Ilha de São Luís-MA.

\section{Conclusão}

Diante do exposto, pode-se verificar que a atividade extrativista de coleta de ostra é feita de forma artesanal e sem recursos tecnológicos, todavia representa uma importante fonte de renda para a comunidade pesqueira da Ilha de São Luís - MA, contribuindo assim para incrementação da economia local.

As condições higiênico-sanitárias adotadas na atividade de extração de ostras até a comercialização são insatisfatórias, indicando falta de boas práticas em todas as etapas ao longo do processo de produção, o que pode representar riscos à saúde da população apreciadora do consumo in natura desse bivalve. Além disso, indica a necessidade de fiscalização dessa atividade, já que os organismos são transportados de forma inadequada e passam muito tempo até chegar ao consumidor final.

Acrescenta-se a necessidade de implantação de políticas públicas direcionadas para o desenvolvimento e aperfeiçoamento da mariscagem, em se tratando de acesso a linha de crédito para o setor, apoio à organização social da categoria, estruturação da cadeia produtiva voltada para a qualidade sanitária do produto e programas educativos que visem a melhoria do grau de instrução dos marisqueiros e capacitação sobre as boas práticas de manipulação e conservação de ostras.

\section{Referências}

ABNT - ASSOCIAÇÃO BRASILEIRA DE NORMAS TÉCNICAS. NBR ISO 22000: Sistema de gestão da segurança de alimentos - requisitos para qualquer organização na cadeia produtiva de alimentos. Rio de Janeiro, 2006. 35p.

BALDIN, N.; MUNHOZ, E. M. B. Snowball (bola de neve): uma técnica metodológica para pesquisa em educação ambiental comunitária. In: CONGRESSO NACIONAL DE EDUCAÇÃO-EDUCERE E SEMINÁRIO INTERNACIONAL DE REPRESENTAÇÕES SOCIAIS, SUBJETIVIDADE E EDUCAÇÃO-SIRSSE, 10., 1., 2011, Curitiba. Anais...Curitiba: PUCPR, 2011, p. 329-341.

BASTI, A. A. et al. Bacterial pathogens in fresh, smoked and salted Iranian fish. Food Control, v. 17, p. 183-188, 2006.

BRAGA, H. F.; FERREIRA, I. M. Quibe cru: qualidade sanitária e perigo à saúde. Revista Brasileira de Pesquisa em Saúde, v. 15, n. 4, p.123-129, 2013.

BRASIL. Ministério da Agricultura, Pecuária e Abastecimento. Lei n ${ }^{\circ} 11.959,29$ de junho de 2009.

Dispõe sobre a Política Nacional de Desenvolvimento Sustentável da Aquicultura e da Pesca, regula as atividades pesqueiras, revoga a Lei no 7.679, de 23 de 
novembro de 1988, e dispositivos do Decreto-Lei no 221 , de 28 de fevereiro de 1967, e dá outras providências. Disponível em: < http://www.planalto.gov.br/ccivil_03/ ato2007-2010/2009/Lei/L11959.htm>. Acesso em: 12 fev. 2015.

CASTILHO-WESRPHAL, G. G. et al. Gestão da qualidade em mercados municipais de pescado. Revista Aquicultura \& Pesca, v. 4, p. 70-74. 2008.

CAVALCANTE, A. L. et al. A arte da pesca: análise socioeconômica da Reserva Extrativista de Canavieiras, Bahia. Informe Gepec, v. 17, n. 2, p. 81-99, 2013.

CAVALCANTI, C. R. et al. Avaliação e diagnóstico das condições de comercialização de alimentos nas feiras livres no estado da Paraíba. Arquivos de Ciências Veterinárias e Zoologia da Unipar, v. 17, n. 3, p. 167-172, 2014.

GUIMARÃES, I. M. et al. Influência da salinidade sobre a sobrevivência da ostra do mangue, Crassostrearhizophorae. Arquivos de Ciências do Mar, v. 41, n. 1, p. 118-122, 2008.

IBGE. Instituto Brasileiro de Geografia e Estatística.

Disponível em: <http://www.cidades.ibge.gov.br/xtras/uf.ph p lang $=\& \operatorname{coduf}=21 \&$ search $=$ maranhao $>$ Acesso em: 27 jan. 2014.

LIMA, M. A. L.; DORIA, C. R. C.; FREITAS, C. E. C. Pescarias artesanais em comunidades ribeirinhas na Amazônia brasileira: perfil socioeconômico, conflitos e cenário da atividade. Ambiente \& Sociedade, v. 15, n. 2, p. 73-90, 2012.

MANESCHY, M. C. Pescadores nos manguezais: estratégias técnicas e relações sociais de produção na captura do caranguejo. In: FURTADO, L. G.; LEITÃO, W.; FIÚZA, A. (ed). Povos das Águas: realidade e perspectivas na Amazônia. Belém, Brasil: MCT/CNPQ, 1993. p. 19-62.

MELLO, A. G. et al. Conhecimento dos manipuladores de alimentos sobre boas práticas nos restaurantes públicos populares do Estado do Rio de Janeiro. Brazilian Journal of Food Technology, v. 13, n. 1, p. 60-68, 2010.

MONTANHINI NETO, R. et al. Influence of environmental variables on the growth and reproductive cycle of Crassostrea (Mollusca, Bivalvia) in Guaratuba Bay, Brazil. Invertebrate Reproduction \& Development, v. 57, n. 3, p. 208-218, 2013.

MONTELES, J. S. et al. Percepção sócio-ambiental das marisqueiras no município de Raposa, Maranhão, Brasil. Revista Brasileira de Engenharia de Pesca, v. 4, n. 1, p. 34-45, 2009.

MOREIRA JUNIOR, W. Alguns aspectos da cadeia produtiva pescado artesanal na região lindeira ao estuário da Baixada Santista/SP. Fórum Ambiental da Alta Paulista, v. 6, p. 679-697, 2010.
NISHIDA, A. K.; NORDI, N.; ALVES, R. R. N. Aspectos socioeconômicos dos catadores de moluscos do litoral paraibano, Nordeste do Brasil. Revista de Biologia e Ciências da Terra, v. 8, n. 1, p. 207-215, 2008.

PEREIRA, M. A. et al. Microbiological quality of oysters (Crassostrea gigas) produced and commercialized in the coastal region of Florianopolis - Brazil. Brazilian Journal of Microbiology, v. 37, n.2, p. 159-163, 2006.

RAMOS, R. J. et al. Microrganismos indicadores de qualidade higiênico-sanitária em ostras (Crassostreagigas) e águas salinas de fazendas marinhas localizadas na Baía Sul da Ilha de Santa Catarina, Brasil. Revista do Instituto Adolfo Lutz, v. 69, n. 1, p. 29-37, 2010.

SANTOS, P. V. C. J. et al. Perfil socioeconômico de pescadores do município da Raposa, Estado do Maranhão. Revista Brasileira de Engenharia de Pesca, v. 6, n. 1, p. $1-14,2011$.

SANTOS, S. S.; EVANGELISTA-BARRETO, N. S.; SILVA, R. A. R. Delineamento do perfil dos consumidores e classificação dos estabelecimentos que comercializam ostras em Valença, Bahia, Brasil. Arquivos de Ciências do Mar, v. 47, n. 2 , p. $72-79,2014$.

VIEIRA, REGINE H. S. F. Microbiologia, higiene e qualidade do pescado - teoria e prática. São Paulo: Varella, 2004. 380p.

WELKER, C. A. D. et al. Análise microbiológica dos alimentos envolvidos em surtos de doenças transmitidas por alimentos (DTA) ocorridos no Estado do Rio Grande do Sul, Brasil. Revista Brasileira de Biociências, v. 8, n. 1, p. 44-48, 2010. 